\title{
Evaluation of the Knowledge and Perceptions about Pharmacovigilance Activities among Pharmacy Students in Nigeria: A Cross-Sectional Study
}

\author{
Osemene Kanayo Patrick and Afolabi Margaret Olubunmi \\ Department of Clinical Pharmacy and Pharmacy Administration, Faculty of Pharmacy, Obafemi Awolowo \\ University, Ile-Ife, Osun State, Nigeria
}

Received: July 14, 2016; Accepted: August 28, 2016; Published (Web): March 19, 2017

\begin{abstract}
Studies on pharmacovigilance (PV) activities in Nigeria focused on perceptions of PV among professional healthcare workers are described here. There is paucity of information on pharmacy students' knowledge about PV activities. Hence, this study, evaluated the knowledge and perceptions of final year pharmacy students about PV activities using descriptive and inferential statistics. A cross sectional study was undertaken in three Nigerian universities with a pretested questionnaire during the period of January and February, 2016. The questionnaire included closed-ended questions on demographic variables and questions designed to achieve the objectives of the study. Data was analyzed with IBM SPSS Statistics 20 and presented in percentages, means, standard deviations and median at 50\% percentile. The mean knowledge score of pharmacovigilance and adverse drug reporting for the final year students was $4.25 \pm 0.18$. There were significant differences in the mean scores of knowledge domain by age groups 21-24 years 4.8 $\pm 0.70,25-30$ years $6.2 \pm 0.84$ and $>30$ years $4.6 \pm 0.72$ at $\mathrm{p}=0.001$; gender: male $4.1 \pm 1.20$ and female $4.4 \pm 0.98$ at $(p=0.0001)$ as well as the current universities attended as follows University 1 with a scrore of $5.1 \pm 1.03$, University 2 had a mean score of $6.3 \pm 0.99$ at $p=0.0120$ and University 3 with a mean score of $4.3 \pm 1.01$ at $p=0.012$. Furthermore, significant difference exist in the mean values of pharmacovigilance knowledge between those who had taking some courses in pharmacovigilance $(7.3 \pm 0.22)$ and those who did not $(4.7 \pm$ 0.13 ) at $p=0.0001$. Generally, the students had inadequate knowledge of PV activities. Therefore, emphasis on relevant PV courses in their curriculum is necessary.
\end{abstract}

Key words: Pharmacy students, ADRs, pharmacovigilance, Activities, Nigeria.

\section{Introduction}

Pharmacovigilance (PV) is the science and activities relating to the detection, assessment, understanding, and prevention of adverse effects or any other drug-related problem (World Health Organization, 2011). The World Health Organization (WHO) defined an adverse drug reaction (ADR) as a response to a drug which is noxious and unintended and which occurs at doses normally used in person for the prophylaxis, diagnosis, of disease, or for the modification of a psychological function (Anshi and Parloop, 2012). Post marketing surveillance is important because it is not possible to determine all the adverse effects of drugs before they are put to use.
Knowledge in pharmacovigilance activities and adverse drug reaction reporting is necessary to reduce incidence of under-reporting, provide more data for rational and safe drug use, promote patients' safety through enhanced care, and provide safe health care practices (Generali, 2014, Moss et al., 1980). Adverse drug reactions (ADRs) have been identified as notable causes of hospitalization, economic losses as a result of poor health outcomes and deaths (Pirmohamed et al., 2004). There are various types of ADRs just as there are different forms of ADR monitoring techniques. Notable techniques for monitoring ADRs are prescription event monitoring, case reports/case series, and voluntary or spontaneous reporting by the patients. (Rawlings,

*Correspondence to: Osemene Kanayo Patrick; Tel: +2348037161268; E-mail: osemenekanayo@gmail.com 
1977). The MEDWATCH training programMEDWATCHlearn, has been identified as a very important tool for training potential ADR reporters (Generali, 2014, United States Food and Drug Administration, 2015).

Some studies conducted in high income countries investigated the knowledge and perceptions of wouldbe healthcare professionals on PV activities and ADR reporting and found that pharmacy students had inadequate knowledge (which could be regarded as low or moderate), poor awareness but positive attitude of PV and ADR reporting (Etminani et al., 2013; Showande and Fakeye, 2013; Elkalmi et al., 2011; Kalari et al., 2011; Gavaza and Bui, 2012; Sullivan and Spooner, 2008; Smith and Webley, 2013). None of the above-mentioned studies, evaluated the students' knowledge about PV across institutions and no study assessed the relationship between the demographic characteristics of would-be healthcare professionals and knowledge of PV.

This study was therefore aimed at investigating the knowledge and perceptions of pharmacy students' about pharmacovigilance as well as the demographic factors that are related to pharmacovigilance activities in Nigeria using a cross-sectional questionnaire-based survey which was conducted in three universities.

In order to achieve the stated objectives, we therefore hypothesize in the null forms as follows that: $\mathrm{Ho}_{1}$ : pharmacy students do not have adequate knowledge of reporting ADRs; $\mathrm{Ho}_{2}$ : there is no relationship between pharmacy students' knowledge about reporting ADRs and age, gender, their current university, previous exposure to $\mathrm{PV}$ subjects and $\mathrm{Ho}_{3}$ : pharmacy students do not have positive perceptions toward ADR reporting.

\section{Materials and Methods}

The study was carried out in January and February, 2016 in Obafemi Awolowo University, Ile-Ife, University of Ibadan, and Olabisi Onabanjo University, Ago-Iwoye. In Nigeria, the National Agency for Food, Drug Administration and Control (NAFDAC), is responsible for collating adverse reports caused by food, drugs and cosmetics from local healthcare professionals and transfer the reports to pharmacovigilance international database in Uppsala (National Agency for Food Drug Administration and Control, 2014; Guidance, Compliance and Regulatory Information, 2013). However, guidelines for monitoring and reporting ADRs are ambiguous and very complex (National Pharmacovigilance Centre, 2007). There are nineteen universities that offer pharmacy course in Nigeria and their curricular are unified (National Universities Commission, 2015).

This cross-sectional study was undertaken with due permission from the institutions and with written consents from respondents who were final year pharmacy students.

Pharmacy students in lower classes (parts 1, 11, 111 and IV) and those in the postgraduate (PG) level were excluded (See Figure 1) from the study because the former had no clinical exposure and have not taken courses in PV subjects. Also, not all the PG students had their first degrees in Pharmacy. Some read allied pharmacy courses such as Botany, Zoology, Chemistry, and Microbiology and decided to get higher degrees in pharmacy related courses.

\section{Questionnaire design and administration of the questionnaire.}

The study adapted the survey instruments used in similar studies to measure knowledge; attitude and perception about PV activities elsewhere (Fadare et al., 2011; Osemene et al., 2012). However, some of the survey instruments were modified to suit the Nigerian environment. A total of 31-item survey instrument of three domains, namely demographics, knowledge and perceptions of final year pharmacy students on ADRs reporting and pharmacovigilance were developed after reviewing a lot relevant literature on the research topic.

The first part of the questionnaire contained 6-item survey questions on demographics such as age, current university, gender, and questions on whether the students have ever heard of the terms adverse drug reaction, pharmacovigilance and if they have taken any course that is related to pharmacovigilance.

The second part contained questions on core issues which assessed students' basic knowledge about pharmacovigilance and adverse drug reaction reporting. The questions had their answers in multiple choice 
format and students were asked to choose the correct answers to the questions. Knowledge on ADR reporting was measured using 10 true or false items. A score of 1 was assigned to each correct answer and 0 for each wrong answer. The maximum score obtainable for the 10 item survey was 10 and the minimum score was 0 . Each student's knowledge about PV activities was determined by adding up all correct answers over the number of maximum obtainable score. The knowledge scores were then computed in percentages. Since the pass mark for pharmacy courses in Nigerian universities is $50 \%$, any respondent who got less than 5 questions correctly out of 10 questions in the survey item $(<5 / 10)$ was deemed to have performed poorly and therefore considered to have poor knowledge about ADR reporting and pharmacovigilance activities. In general, the detail explanation of how undergraduate pharmacy students are graded in Nigeria are as follows: scores $<50 \%$ (poor), 50\%-60\% (good), 60\%-69\% (very good) and $>70 \%$ (Excellent).

\section{FLOW-CHART (AS PER STROBE)}

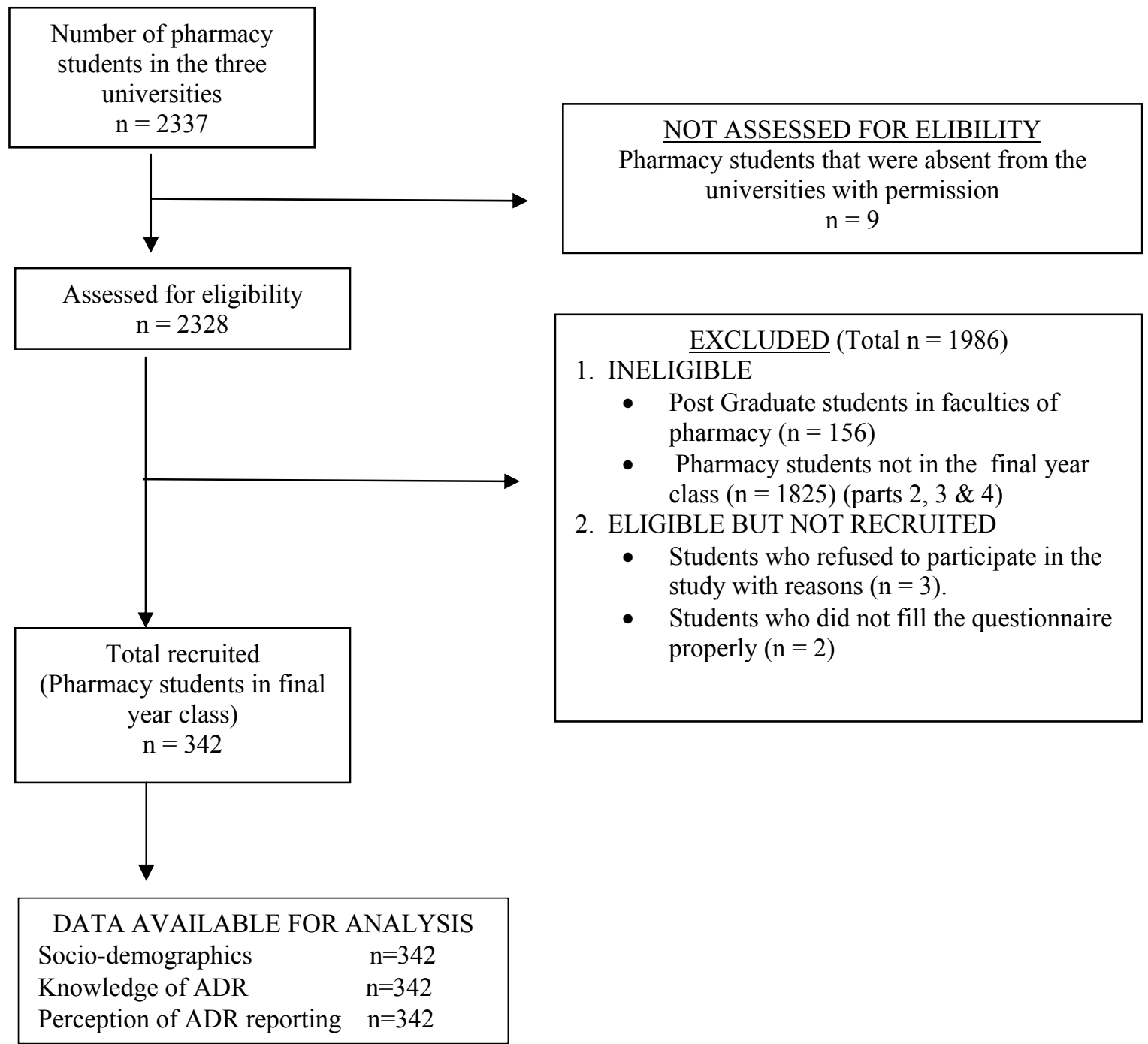

Figure 1. A description of participants inclusive/exclusive is presented in a flow chart as per STROBE- Strengthening the Reporting of Observational Studies in Epidemiology. 
The third section of the questionnaire contained 15 survey items which evaluated the perceptions of pharmacy students toward adverse drug reporting. Students' perceptions of ADR reporting were measured on survey statements rated on a 5-point Likert scale of $1=$ strongly disagree, $2=$ disagree, $3=$ neutral, $4=$ agree, and $5=$ strongly agree. The questionnaires were structured and contained mostly closed-ended questions whose answers were not mutually exclusive. The questionnaire was pretested and used to make necessary corrections and modifications before they were administered. Before the students filled the questionnaire, they were informed that completing and returning the questionnaire would be regarded as their informed consent to participate in the study. Therefore the study was non-invasive. The students were also assured of the anonymity and confidentiality of any information provided by them by in the questionnaire. They were also asked to work independently by avoiding any interaction amongst them and to avoid consulting reference materials. This was done to ensure that actual individual students' knowledge about PV activities was employed in filling the questionnaire.

\section{Statistical analysis}

Data was analyzed with IBM SPSS Statistics 20 and presented in percentages, means,standard deviations and median at $50 \%$ percentile. The case of missing data was addressed using Listwise deletion technique (complete case analysis).This was done by omitting those cases with missing data and analysis was run on remaining data.

Knowledge score of the respondents about PV was computed and presented in percentages and means. The association between knowledge score and the demographic variables of gender and the presence of $\mathrm{PV}$ courses in the universities was determined using the independent student $t$-test because there was one independent variable gender with two categories (male/female) and one continuous dependent variable (PV knowledge). While the association between respondents' knowledge of PV with their demographic variables were examined using t-testsand analysis of variance (ANOVA).
Perceptions of the final year pharmacy students about PV activities were presented with descriptive statistics such as frequency at $50 \%$ percentile and mean. These were used in describing respondents' opinion to specified statements in ordinal scale. The ranked variables were evaluated using Kruskal-Wallis and Mann Whitney $U$ tests as appropriate at $\mathrm{p} \leq 0.05$.

\section{Results}

A total of 342 respondents properly filled the questionnaire. Data obtained were used for analysis. Test of reliability of the final copy of the questionnaire gave a cronbach alpha value of 0.721 . Majority of the final year pharmacy students were males (65.2\%). Most respondents were between 21 to 30 years of age with a mean age of $25.5 \pm 4.3$ years. Only $2.6 \%$ of them were above 30 years of age. The mean knowledge score of pharmacovigilance and adverse drug reporting for the final year students was $4.25 \pm 0.18$. There were significant differences in the mean scores of knowledge domain by age groups 21-24 years 4.8 $\pm 0.70,25-30$ years $6.2 \pm 0.84$ and $>30$ years $4.6 \pm 0.72$ at $\mathrm{p}=0.001$; gender: male $4.1 \pm 1,20$ and female $4.4 \pm 0.98$ at ( $p=0.0001)$ as well as the current universities attended as follows University 1 with a mean knowledge value of 5.1 \pm 1.03 , University 2 with a mean knowledge value of $6.3 \pm 0.99$ at $p=0.0120$ and University 3 with a mean knowledge value of $4.3 \pm 1.01$ at $p=0.012$. Furthermore, significant difference exist in the mean values of pharmacovigilance knowledge between those who had taking some courses in pharmacovigilance $7.3 \pm 0.22$ and those who did not $4.7 \pm 0.13$ at $p=0.0001$.

Based on the results obtained in table 1, we accept the null hypothesis $\mathrm{H}_{\mathrm{O} 1}$ which states that pharmacy students have inadequate knowledge $(4.25 \pm 0.18)$ of reporting ADRs and reject the alternative hypothesis. Furthermore, the second hypothesis $\left(\mathrm{Ho}_{2}\right)$ which states that there is no relationship between pharmacy students' knowledge about reporting ADRs and age, gender, their current university, and previous exposure to PV subjects is rejected and the alternative hypothesis accepted.

The relationship between the mean knowledge score of Nigerian final year pharmacy students with their demographic characteristics is presented in table 1. 
In table 2, less than half of the respondents $(n=165,48.2 \%)$ were able to indicate the organization (NAFDAC) whose prime duty is to collate and document various ADRs reports in Nigeria. Also, respondents' knowledge on what the terms adverse drug reactions and pharmacovigilance are, were $(n=169) 49.1 \%$ and $(n=173) 50.6 \%$ respectively. Very poor performance by respondents in the knowledge domain was recorded from the answer to question on the types of ADRs to be documented ( $n=118,34.5 \%)$. About half of the respondents $(n=176,51.5 \%)$ disagreed that ADRs caused by herbal medicines should be reported. Also only half $(\mathrm{n}=174,50.9 \%)$ of the pharmacy students knew that all cases of ADRs should be reported. However, only few respondents $(\mathrm{n}=21,6.1 \%)$ could provide the correct answer to whether or not, all possible adverse reactions to any drug could be known in the pre-marketing phase of drug production process. Nevertheless, respondents' knowledge on types of ADR reporting system, guidelines for reporting them and types of ADRs they know was below average. Final year pharmacy students' knowledge concerning ADRs reporting in Nigeria is presented in Table 2.

Table 1. Relationship between the knowledge score of Nigerian final-year pharmacy students with their demographic characteristics $(\mathrm{N}=342)$.

\begin{tabular}{|c|c|c|c|c|}
\hline Demographics & Response rate $\mathrm{n}(\%)$ & $\begin{array}{l}\text { Mean knowledge } \\
\text { score (SD) }\end{array}$ & Values & $p$ \\
\hline \multicolumn{5}{|l|}{ Gender } \\
\hline$\overline{\text { Male }}$ & $223(65.2)$ & $4.1(1.20)$ & & \\
\hline Female & $119(34.8)$ & $4.4(0.98)$ & 10.65 & $0.0001^{\mathrm{a}}$ \\
\hline \multicolumn{5}{|l|}{ Age (years) } \\
\hline $21-24$ & $120(35.1)$ & $4.8(0.70)$ & & \\
\hline $25-30$ & $213(62.3)$ & $6.2(0.84)$ & & \\
\hline$>30$ & $9(2.6)$ & $4.6(0.72)$ & 129.330 & $0.0001^{\mathrm{b}}$ \\
\hline \multicolumn{5}{|c|}{ Pharmacovigilance course } \\
\hline Yes & $263(76.9)$ & $7.3(0.22)$ & & \\
\hline No & $79(23.1)$ & $4.7(0.13)$ & 16.637 & $0.0001^{\mathrm{a}}$ \\
\hline \multicolumn{5}{|c|}{ No. of students in each university } \\
\hline $1(n=110)$ & $107(31.3$ & $5.1(1.03)$ & & \\
\hline $2(n=143)$ & $141(41.2)$ & $6.4(0.99)$ & & \\
\hline $3(n=94)$ & $94(27.5)$ & $4.3(1.01)$ & 142.041 & $0.0120^{\mathrm{b}}$ \\
\hline
\end{tabular}

a................Independent t-test

b................Analysis of Variance

Table 2. Final-year pharmacy students' knowledge concerning ADRs reporting in Nigeria (N=342).

Survey Item

Respondents who got the correct

answers to survey questions (items) No. (\%)

1. What do you understand by the term adverse drug reactions?

$168(49.1)$

2. What is pharmacovigilance?

$173(50.6)$

3. Which types of ADR should be documented?

$118(34.5)$

4. What type of ADR reporting system do we have in Nigeria?

$143(41.8)$

5. All ADRs should be reported.

$174(50.9$

6. There are no guidelines for reporting ADRs in Nigeria.

$167(48.8)$

7. What types of ADRs do you know?

$147(43.0)$

8. ADRs caused by herbal medicines are neither documented nor reported.

$176(51.5)$

9. All ADRs are known before a drug is marketed.

$21(6.1)$

10. Which organization should cases of ADRs be reported to in Nigeria?

$165(48.2)$ 
Almost all the students $(n=339,99.1 \%)$ indicated that they have acquired enough knowledge to enable them to report ADRs (Survey Statement 1 in table 3). Also most of the students $(n=318,92.98 \%)$ believed that incorporating more clinical courses into the pharmacy curriculum will improve pharmacy students' knowledge to report ADRs (Survey Statement 12). Also more than two-thirds $(n=273,79.83 \%)$ of the students were of the opinion that pharmacovigilance courses should be taught at higher levels in pharmacy schools (Survey Statement 14). A very high number of the students $(n=321,93.86 \%)$ were of the opinion that pharmacists' involvement in reporting ADRs would impact positively on pharmacovigilance activities (Survey Statement 11). About two-third of the students $(n=211,61 \%)$ believed that late or non-reporting of ADRs could pose major

Table 3. Final-year pharmacy students' perceptions about ADR reporting in Nigeria ( $N=342)$.

\begin{tabular}{|c|c|c|c|c|c|c|c|c|c|c|c|}
\hline $\mathrm{S} / \mathrm{N}$ & Survey statements & $\begin{array}{c}\mathrm{SD} \\
1\end{array}$ & $\begin{array}{l}\mathrm{D} \\
2\end{array}$ & $\begin{array}{c}\mathrm{N} \\
3\end{array}$ & $\begin{array}{c}\text { A } \\
4\end{array}$ & $\begin{array}{c}\mathrm{SA} \\
5\end{array}$ & $\begin{array}{c}\text { Median } \\
(50- \\
\text { percentile })\end{array}$ & Mean & $\begin{array}{l}\text { Kruskal } \\
\text { Wallis }\end{array}$ & $\begin{array}{l}\text { Mann- } \\
\text { Whitney } \\
\text { U }\end{array}$ & $\begin{array}{c}\mathrm{p} \\
\text { value }\end{array}$ \\
\hline 1 & $\begin{array}{l}\text { I believe that I have acquired enough } \\
\text { knowledge to enable me to report ADRs. }\end{array}$ & 1 & 1 & 1 & 126 & 213 & 5.00 & 4.6 & 262 & 5593 & .010 \\
\hline 2 & $\begin{array}{l}\text { Pharmacovigilance should be taught at all } \\
\text { levels in pharmacy schools. }\end{array}$ & 120 & 60 & 50 & 72 & 40 & 2.00 & 2.6 & 289 & 150 & .020 \\
\hline 3 & $\begin{array}{l}\text { Majority of ADR reports should come } \\
\text { from pharmacists. }\end{array}$ & 108 & 91 & 80 & 32 & 31 & 2.00 & 2.4 & 300 & 672 & .023 \\
\hline 4 & $\begin{array}{l}\text { I believe that late or non- reporting of } \\
\text { ADRs could pose major health problems. }\end{array}$ & 61 & 50 & 20 & 88 & 123 & 4.00 & 3.5 & 289 & 238 & .001 \\
\hline 5 & $\begin{array}{l}\text { I believe that adverse reactions caused by } \\
\text { herbal medicines should be reported }\end{array}$ & 130 & 100 & 75 & 7 & 30 & 2.00 & 2.14 & 284 & 326 & .041 \\
\hline 6 & $\begin{array}{l}\text { Monetary incentives to health workers } \\
\text { may improve ADRs reporting. }\end{array}$ & 16 & 65 & 10 & 101 & 150 & 4.00 & 3.9 & 260 & 1845 & .021 \\
\hline 7 & $\begin{array}{l}\text { Pharmacy students can perform ADR } \\
\text { reporting during their clerkship. }\end{array}$ & 35 & 43 & 75 & 80 & 109 & 4.00 & 3.54 & 283 & 350 & .031 \\
\hline 8 & $\begin{array}{l}\text { I believe that government could improve } \\
\text { ADR reporting in Nigeria through } \\
\text { advocacy }\end{array}$ & 94 & 64 & 80 & 95 & 9 & 3.00 & 2.59 & 299 & 488 & .022 \\
\hline 9 & $\begin{array}{l}\text { I believe ADR reporting is an integral part } \\
\text { of pharmaceutical care }\end{array}$ & 31 & 68 & 53 & 69 & 121 & 4.00 & 3.53 & 286 & 119 & .001 \\
\hline 10 & $\begin{array}{l}\text { Pharmacists should not be barred from } \\
\text { reporting ADRs as is the case in some } \\
\text { countries }\end{array}$ & 154 & 121 & 36 & 11 & 20 & 2.00 & 1.89 & 248 & 1794 & .001 \\
\hline 11 & $\begin{array}{l}\text { I believe that pharmacists' involvement in } \\
\text { reporting of ADRs would impact } \\
\text { positively on pharmacovigilance activities }\end{array}$ & 5 & 2 & 14 & 198 & 123 & 4.00 & 4.26 & 234 & 238 & .042 \\
\hline 12 & $\begin{array}{l}\text { I believe that if the identities of ADR } \\
\text { reporters are disclosed reporting rate will } \\
\text { increase }\end{array}$ & 10 & 5 & 9 & 53 & 265 & 5.00 & 4.63 & 215 & 8687 & .001 \\
\hline 13 & $\begin{array}{l}\text { I believe that if the identities of } \mathrm{ADR} \\
\text { reporters are not disclosed reporting rate } \\
\text { will decrease }\end{array}$ & 58 & 21 & 44 & 98 & 121 & 4.00 & 3.59 & 288 & 119 & .002 \\
\hline 14 & $\begin{array}{l}\text { Pharmacovigilance should be taught only } \\
\text { at higher levels in pharmacy schools }\end{array}$ & 32 & 17 & 20 & 88 & 185 & 5.00 & 4.04 & 245 & 3927 & .010 \\
\hline 15 & $\begin{array}{l}\text { I believe that adverse reactions caused by } \\
\text { cosmetics should be reported }\end{array}$ & 126 & 78 & 29 & 16 & 93 & 2.00 & 2.63 & 300 & 95 & .031 \\
\hline
\end{tabular}

$\mathrm{SD}=$ Strongly disagree, $\mathrm{D}=$ Disagree, $\mathrm{N}=$ Neutral, $\mathrm{A}=$ agree and $\mathrm{SA}=$ Strongly agree. $\mathrm{p}<0.05$.

health problems (Survey Statement 4). Just a little above half of the number of students $(n=190,55 \%)$ believed that ADR reporting is an integral part of pharmaceutical care (Survey Statement 9). A 
reasonable high number of the students $(n=251,73.4 \%)$ were of the opinion that monetary incentives to health workers may improve ADR reporting (Survey Statement 6). More than half $(n=204,59.7 \%)$ of the total number of pharmacy students wrongly believed that adverse reactions caused by cosmetics should not be reported (Survey Statement 15). More than half ( $\mathrm{n}=$ $189,55.26 \%$ ) of the students also claimed that they can perform ADR reporting during their clerkship (Survey Statement 7). Most of the students perceived that adverse drug reactions caused by herbal medicines should be reported (Survey Statement 5). More than half $(n=180,52.63 \%)$ of the students were of the opinion that pharmacovigilance should not be taught at all levels in pharmacy schools in Nigeria (Survey Statement 2). All the survey statements in table 3 were significant at $\mathrm{p}=0.05$. Therefore, the null hypothesis $\mathrm{H}_{03}$, was rejected and its alternative form accepted.

\section{Discussion}

The knowledge of Nigerian pharmacy students' about ADR reporting and pharmacovigilance activities was inadequate. This result corroborates with the findings of previous studies conducted elsewhere (Etminani et al., 2013; Showande and Fakeye, 2013; Elkalmi et al., 2011; Kalari et al., 2011; Gavaza and Bui, 2012; Sullivan and Spooner, 2008; Smith and Webley, 2013). The significant differences in the mean knowledge score on PV activities by gender $(p=.0001)$ could be attributed to the differences in their levels of interest in PV subjects. Female students had better knowledge of ADR reporting than their male counterparts. This contradicts the result of similar studies conducted elsewhere (Kingston et al., 2015;Muhammad et al.,2015; Abdullahi et al., 2015). Furthermore, most pharmacy students' inability to provide accurate answers to survey statement 9 in table 2 (all ADRs are known before a drug is marketed) is a flaw in their knowledge of PV activities, in spite that they claimed to have acquired enough knowledge to monitor and report ADRs (Survey Statement 1 in table 3).

However, reasons for pharmacy students' poor knowledge of ADR monitoring could be due to insufficient course content on PV in their universities' curriculam (Etminani et al.,2013; Showande and Fakeye,2013),inadequate training on how ADRs reporting forms are used, and inadequate hands-on experience (Generali et al., 2014) on ADRs reporting. Variations in knowledge of PV activities amongst students in the three universities could be attributed to differences in emphasis in the teaching of ADR reporting. As mentioned elsewhere in a similar study, this disparity in knowledge about PV was attributed to the locations of the universities (Kingston and Mari, 2015). Two universities where this study was undertaken, were located in urban centres with very large tertiary or teaching hospitals, while the third one was sited in a remote area and has a secondary health facility. Consequently, pharmacy students in the universities with tertiary hospitals which usually have large patient population, would have higher probability of coming in contact with patients with and reports of ADRs than their counterparts who were being trained in secondary health facilities; especially during their clerkship programme. Furthermore, the high variability in knowledge about PV, portends wide inequalities in the standard of pharmacy education in PV subjects across Nigerian universities. Bridging this knowledge gap could entail an increase in the course content in PV subjects.

A majority of the pharmacy students did not know ADR types, reporting systems, guidelines, and the organization where ADR reports should be sent to.The clerkship programme would provide a good opportunity for the students to have better insights on ADR types. In clinical pharmacy clerkship, students are posted to hospital wards to join other medical team for routine ward rounds in order to review prescriptions (where necessary), monitor patients' drug use and therapeutic outcome and learn vital issues on medication safety. Also, pharmacy students are exposed to pharmacysupervised experiences (externship) in selected community pharmacies and at the university health centres as partial requirement for the award of either the Bachelor of Pharmacy (B. Pharm.) or Doctor of Pharmacy (Pharm. D.) degree. The main goal of the entire exercise is to among other things, train the students in practical clinical pharmacy activities such as scrutinizing prescription for completeness, take medication history which would help in the monitoring 
of patient compliance, keep medication profiles, monitor drug-drug interactions, adverse reactions and learn how to report such reactions (Hepler and Strand,1990). All these are intended to prepare the students for future good quality clinical practice and maintain a high standard of pharmaceutical education. In addition, pharmacy students are expected to have adequate knowledge concerning the process, procedure, and importance of adverse drug reaction reporting (Kalari et al., 2011).However, behaviour change theories did suggest that education alone may not be enough to improve knowledge of PV. Instead, hands-on experience during clerkships is needed for students to grasp the full extent of PV activities.

Nevertheless, most of the students disagreed that adverse reactions caused by cosmetics should be reported (survey statement 15). Cosmetics, arguably represent the commonest and most widely used products. Most times cosmetics are regarded as daily needs. However, more often than not, a lot of people do not really have a clear understanding of what cosmetics are. The main issue is whether a product is a cosmetic or a drug or both. Sometimes, a product can be a cosmetic and drug. This happens when the product has two or more intended uses. For instance antidandruff shampoo is used for dual purposes as hair cleanser and antidandruff while deodorants act as antiperspirants, moisturizers and makeup marketed with sun-protection claims (Guidance, Compliance and Regulatory Information, 2013). Anyway, this notable misconception associated with ADRs reporting arising from the use of cosmetics could be as a result of the students' lack of experience in ADR reporting guidelines. Hence they did not know what and what not to be reported.

Most of the students were of the opinion that monetary incentives to health workers could improve ADR reporting. This result is similar to the findings of Inman 1996, who reported that lack of monetary incentives to ADRs reporters was one of the prominent "seven deadly sins that caused ADR underreporting. Monetary incentives for reporting ADRs have influenced the attitudes of some health workers toward ADRs reporting (Inman, 1996). However, commercializing such a mandatory and fundamental health activity could be prone to abuse and froth with immense danger because the quest to make money could override the desire to render quality service. Therefore, other strategic approaches to incentivize pharmacists to report ADRs include but not limited to giving healthcare promoters access to ADRs data. Making ADR reporting forms and data easy to obtain, interpret, and use could encourage and perhaps improve reporting. An improvement in technology could help address the challenges of entering ADR reports into internal database. In a low income country such as Nigeria, it is an enormous task entering data into any electronic database due to poor internet connectivity, inadequate and epileptic power supply, weak technological capabilities and inadequate infrastructural facilities (Nwokike, 2015). Also, incentivizing pharmacists and other health professionals could be done in terms of payment of nominal fees to cover time and efforts, embarking on continuous medical education programmes for improving healthcare service delivery which includes PV activities, and enlisting the services of the private sector as evidenced in vaccination service delivery in India (Sharma et al., 2016). In addition, other non-monetary incentives could come in form of flexible work hours, training, the creation of a pleasant work environment, and granting sabbaticals to ADR reporters (Ballentine et al., 2002). $1 \mathrm{n}$ fact research revealed that training of health workers has increased in 10-folds, ADR reporting in Portugal (Figueires et al., 2006).

A remarkably high number of the students believed that pharmacist participation in ADRs reporting would have positive impact on PV activities. This finding is comparable with the result obtained elsewhere (Moss et al., 1980). In literature, it was revealed that ADR monitoring and reports emanated from community and hospital pharmacists (Generali 2014; Moss et al., 1980; United States of America Food and Drug Administration 2015). Pharmacists in these settings come in contact with patients easily and could evaluate the patients' medication profile and give professional advice that could ensure better medication outcome even at reduced cost.

Meanwhile, in Nigeria, there is a deliberate effort to introduce and train pharmacy students to clinicalbased courses. This is because pharmacy education is becoming more patient focused and gradually shifting 
from molecular chemistry and formulae, to clinicalbased practices which lay much emphasis on pharmaceutical care. Advocates of pharmaceutical care continue to make case for more patient centered pharmaceutical practice (National University Commission, 2015; Aguwa, 2009). Globally, there seems to be a shift in practice by pharmacists and nurses in view of their expanded roles. The two major strategic approaches adopted in this shift are "taskshifting" and "non-physician prescribing" especially in places where there are acute shortage of physicians in low and high income countries. These actions by pharmacists and nurses have reduced the workload of physicians, increased the availability and accessibility to healthcare, helped scrutinize prescriptions, offered high quality cost-effective care to more patients and improved ADR monitoring and reporting (Sharma et al. ,2013; Callahan et al., 2011). Furthermore, a notable study reported that clinical pharmacist intervention (where there was acute shortage of physicians) improved the management of Chronic Obstructive Lung Disease (Suhaj et al., 2013). In fact, the involvement of clinical pharmacists in medical wards improved the monitoring and reporting of ADRs elsewhere (Moss et al., 1980). Also, final-year pharmacy students reportedly exhibited more knowledge and positive attitudes about ADRs in terms of their capacity to handle and report ADRs than final-year medical students (Muhammad et al., 2015). In addition, pharmacy students who responded to survey item 9 in the perception domain believed that PV activities could be regarded as an integral part of pharmaceutical care. In addition, a comprehensive knowledge in clinical pharmacy courses and practical exposure to cases in the hospitals which the clerkship programme is meant to offer remains a unique opportunity that pharmacy students must utilize in order to understand and acquire the skills for ADR reporting.

The major strength of this study is that international readers could use the results as a basis of comparison with similar studies carried out in high income countries. However, limitations associated with this study are that only three universities were examined, and limitations associated with questionnaire-based studies such as subjective responses, cannot be completely ruled out. However, results obtained from this study would serve as templates for further studies in Pharmacovigilance.

\section{Conclusion}

The study revealed that Nigerian pharmacy students have inadequate knowledge of pharmacovigilance activities, but have positive perceptions towards ADR reporting. Therefore, pharmacy students' educators should intensify the teaching of how to report ADRs and give more emphasis on PV courses in the curriculum in order to improve students' knowledge of and future practice of ADR reporting.

Competing interest: The authors declare that they have no competing interests.

Declaration: This study was carried out by the authors and the contents of this paper have not been published before or submitted elsewhere for publication. OKP the corresponding author, designed the study, administered the questionnaire, analyzed the data $(60 \%)$. AMO the co-author, designed the questionnaire, conducted the pilot study and wrote the first draft (40\%). Both authors wrote the final draft and approved it for submission.

\section{References}

Abdullahi, R.A., Bashir, A.Z.C., Khalid, G.M., andMainul, H.2015. Perception of Nigerian medical students on adverse drug reaction reporting. J. Adv. Pharm. Technol. Res. 6, 154-158.

Aguwa, C.N. 2009. Pharmacy Curriculum Review: Clinical Pharmacy In: Pharmacy Education in Nigeria. Akubue, P.I and Adenike, F.B. eds. Published by Pharmacists Council of Nigeria.

Anshi, S. andParloop, B. 2012.Comparative evaluation of adverse drug reaction reporting forms for introduction of a spontaneous generic ADR form. J. Pharmacol Pharmacother.3, 228-232.

Ballentine, A., Mckenzie, N., Wysocki, A., and Kepner, K. 2002. The role of monetary and non-monetary incentives in the work place as influenced by career stage.

Callahan, M., Ford, N., and Schneider, H. 2010. Systematic review of task-shifting for HIV treatment and carein Africa. Human Res. Health. 8, 8 .

Elkalmi, R.M., Hassali, M.A., Ibrahim, M.I., Widodo, R.T., Efan, Q.M., Hadi, and M.A.2011. Pharmacy students' knowledge and perceptions about pharmacovigilance in Malaysian Public Universities. Am. J. Pharm. Edu.75, 5. 
Etminani, M., Isfahan, S.M., Amin, R., Mehrdad, A, Leila, k. and Kaveh, E. 2013. Adverse drug reactions: knowledge, attitude and perceptions of pharmacy students. J. Pharm. Care.1, 145-148.

Fadare, J.O., Enwere, O.O.,Afolabi, O.A., Chedi, B.A.Z., and Musa, A. 2011. Knowledge, attitude and practice of adverse drug reaction reporting among healthcare workers in a tertiary centre in Northern Nigeria. Trop J. Pharm. Res.10, 235-242

Figueires, A., Herdeiro, M.T., Polonia, J. and Gestal-Otero, J.J. 2006. An educational intervention to improve physicians reporting of adverse drug reaction: A clusterrandomized controlled trail. J. Am. Med. Assoc. 296, 1086-93.

Gavaza, P., and Bui, B. 2012. Pharmacy students' attitudes toward reporting serious adverse drug events. Am. J. Pharm.Edu. 76, 194.

Generali, J.A. 2014. Adverse Drug Event Reporting: Awareness Is Not Enough. Hosp Pharm. 49, 110-111. Doi: 10.1310/hpj4902-110.

Guidance, Compliance and Regulatory Information. 2013. How can a product be both a cosmeticdrug? www. fda.gov/cosmetics/guidancecomplianceregulatoryinform ation (Accessed13/04/2015).

Hepler, C. and Strand, L. 1990. Opportunities and responsibilities in pharmaceutical care. Am. J. Hosp. Pharm. 47, 533-543

Inman, W.H. 1996.Attitudes to adverse drug-reaction reporting.Br J. Clin. Pharmacol. 433- 435.

Kalari, S., Dormerunno, M., Zvenigorodsky, O. and Mohan, A. 2011. Pharmacy Student Perceptions of Adverse Event Reporting. Am. J. Pharm. Edu. 75, 131 doi.105688/ajpe 757131

Kingston, R., Mari, K, and Shashinar, N. 2015.Pharmacy students' Knowledge and Perceptions about ADRs reporting and Pharmacovigilance. Saudi Pharm. J. doi: 10.1016/jjsps.03-021.

Moss, R.L., Garnett, W.R. and Steiner, K.C.1980.Physicians' attitudes towards pharmacists counseling patients on adverse drug reactions. Am. J. Hosp. Pharm. 37, 243249.

Muhammad, U.K., Akram, A., Areeba, E., Syed, A.R., Ayesha, S. and Kazim, H. et al. 2015. Comparism of the Knowledge, attitudes, and perception of barriers regarding

adverse reaction reporting between pharmacy and medical students in Pakistan. J. Edu. Eval. Health Prof. 12, 28.

National Agency for Food Drug Administration and Control. 2014.Pharmacovigilance in Nigeria Lagos.
National Pharmacovigilancecentre (PVG/FDIC), NAFDAC, Nigeria. 2007. Safety of medicines in Nigeria: A guide for detecting and reporting adverse drug reactions - why health professionals must act.

National Universities Commission. 2015. Available at: www.nuc.edu.ng (Accessed 25/2/2015).

Nwokike, J. 2015. Monitoring Adverse Drug Reactions in the Public Health Programs: The case of the Nigeria TB programme. Submitted to the US Agency for International Development by the TBCAP Project Available at www.www.apps.who.int/medicinedocs/ documents/s18400en.pdf.Accessed $13^{\text {th }}$ May, 2015.

Osemene, K.P., Ayeni, A.I. and Afolabi, M.O. 2012. The role of community pharmacists in monitoring adverse drug Reactions in Nigeria. J. Pharm. Health Serv. 3, 197-204. Doi 10. 1111/j. 1759-8893.2012.00100.X

Pirmohamed, M., James, S. Meakin, S. Green, C., Scott, A.K., and Walley, T.J., et al. 2004. Adverse drug reactions as cause of admission to hospital: perspective analysis of 18,820 patients. Br. Med. J. 329, 15-19.

Rawlings, M.D. and Thompson, J.W.1977.Pathogenesis of adverse drug reactions. In: Davis DM, ed. Textbook of adverse drug reactions: Oxford: Oxford University Press.

Sharma, A., Kaplan, W.A., Chokshi, M., Zodpey and S.P. 2016. Role of the private sector in vaccination service delivery in India: evidence from private-sector vaccine sales data, 2009-12. Available athttp://ww. ncbi.nlm. nih.gov/pubmed/269768039 (Accessed July 22, 2016).

Showande, J.S. and Fakeye, T.O. 2013. The Concept of Adverse Drug Reporting: Awareness among Pharmacy Students in a Nigerian University. Internet J. Med. Update, 8, 24-60.

Smith, M.P., and Webley, S.D.2013.Pharmacovigilance teaching in UK undergraduate pharmacyprogrammes. Pharmacoepidemiol Drug Saf. 2013: 22, 223-228.

Suhaj A, Manu M.K., Unnikrishnan M.K, Vijayanarayana K, Mallikarjuna Rao C. Effectiveness of clinicalpharmacist intervention on health-related quality of life in chronic obstructive pulmonary disorder patients-a randomized controlled study. 2016; J. Clin. Pharm. Thera 41, 78-83. Doi: $10.1111 /$ jcpt.12353.

Sullivan, K.M., and Spooner, L.M. 2008.Adverse-drug reaction reporting by pharmacy students in a teaching hospital. Am. J. Health Syst. Pharm .65, 1177-9

US Food and Drug Administration.2015. MEDWATCHlearn.

http//www.accessdata.fda.gov/scripts/MedWatchLearn/. Accessed February 17, 2015.

WHO collaborating centre for international drug monitoring, the Uppsala monitoring centre. Adverse reactions and adverse reaction monitoring training course.2011. (Accessed August 14, 2011). Available at http://www.whoumc.org/DynPage.asx?id=13140 andmn $=1514 \# 6$. 


\section{Appendix 1. QUESTIONNAIRE USED FOR THE STUDY}

\section{Section A (Demographic Profile) \\ Background information of final year pharmacy students}

1. What is your sex? Male $\square \quad$ Female

2. Age up to $20 \quad \square \quad 21-24 \quad \square \quad 25-30 \quad \square>30$

3. Please write the name of your university in the space below

4. How many are you in your class?

5. Have you heard of the terms adverse drug reactions and pharmacovigilance? Yes $\square \quad$ No

6. Did you take any pharmacovigilance course? $\quad$ Yes $\square \quad$ No

Section B

Evaluating the knowledge of pharmacy students about PV activities in Nigeria

Please tick on the most appropriate option.

1. What do you understand by the term adverse drug reactions ADRs?

(a) A noxious and unintended response to a drug at doses normally used in man

(b) A noxious and intended response to a drug at doses normally used in man

(c) A noxious and unintended response to a drug at abnormal doses used in man

(d) A noxious and intended response to a drug at abnormal doses used in man

2. What is Pharmacovigilance?

(a) The science detecting the type and incidence of ADR after drug is marketed

(b) The science of monitoring ADR's occurring in a Hospital

(c) The process of improving the safety of the drug

(d) The detection, assessment, understanding and prevention of adverse effects

3. Which types of ADRs should be documented?

(a) Suspected ADRs for a new drug

(b) Suspected ADRs for an old drug

(c) Suspected severe ADRs for any drug

(d) All of the above

4. Which type of reporting system do we have in Nigeria?

(a) Prescription event monitoring

(b)Spontaneous reporting system

(c) Case reports

(d) Meta-Analysis

5. All ADRs should be reported

(a)Yes

(b)No 

(c) Can't say
(d) May be

6. There are no guidelines for reporting ADRs in Nigeria
(a) Yes
(b) No
(c) Can't say
(d) May be

7. What types of ADRs do you know?
(a) Types A, B, C, D \& E
(b) Types A, B, C, D \& F
(c) Types A, B, C, D \& G
(d) Types A, B, C, D \& H

8. ADRs caused by herbal medicines are neither documented nor reported
(a) Yes
(b) No
(c) Can't say
(d) May be

9. All ADRs are known before a drug is marketed
(a) Yes
(b) No
(c) Can't say
(d) May be

10. Which organization should cases of ADRs be reported to in Nigeria?
(a) Pharmacists Council of Nigeria (PCN)
(b) Pharmaceutical Society of Nigeria (PSN)
(c) National Agency for Food, Drug Administration and Control (NAFDAC)
(d) National Drugs Law Enforcement Agency (NDLEA) 


\section{SECTION C}

\section{Evaluating the perceptions of pharmacy students about ADRs reporting}

Indicate your level of agreement with the under-listed statements on a 5-point scale by ticking the boxes below as SD (1) = Strongly disagree, D (2) = Disagree, N (3) = Neutral, A (4) = Agree, and SA (5) = Strongly agree

\begin{tabular}{|c|c|c|c|c|c|c|}
\hline $\mathrm{S} / \mathrm{N}$ & SURVEY STATEMENTS & $\begin{array}{c}\text { SD } \\
1\end{array}$ & $\begin{array}{l}\mathrm{D} \\
2\end{array}$ & $\begin{array}{l}\mathrm{N} \\
3\end{array}$ & A & $\begin{array}{c}\text { SA } \\
5\end{array}$ \\
\hline 1 & $\begin{array}{l}\text { I believe that I have acquired enough knowledge to enable me report } \\
\text { ADRs. }\end{array}$ & & & & & \\
\hline 2 & Pharmacovigilance should be taught at all levels in pharmacy schools. & & & & & \\
\hline 3 & Pharmacovigilance should be taught at all levels in pharmacy schools. & & & & & \\
\hline 4 & $\begin{array}{l}\text { I believe that late or non- reporting of ADRs could pose major health } \\
\text { problems. }\end{array}$ & & & & & \\
\hline 5 & $\begin{array}{l}\text { I believe that adverse reactions caused by herbal medicines should be } \\
\text { reported }\end{array}$ & & & & & \\
\hline 6 & Monetary incentives to health workers may improve ADRs reporting. & & & & & \\
\hline 7 & Pharmacy students can perform ADR reporting during their clerkship. & & & & & \\
\hline 8 & $\begin{array}{l}\text { I believe that government could improve ADR reporting in Nigeria through } \\
\text { advocacy }\end{array}$ & & & & & \\
\hline 9 & I believe ADR reporting is an integral part of pharmaceutical care & & & & & \\
\hline 10 & $\begin{array}{l}\text { Pharmacists should not be barred from reporting ADRs as is the case in } \\
\text { some countries }\end{array}$ & & & & & \\
\hline 11 & $\begin{array}{l}\text { I believe that pharmacists' involvement in reporting of ADRs would impact } \\
\text { positively on pharmacovigilance activities }\end{array}$ & & & & & \\
\hline 12 & $\begin{array}{l}\text { I believe that if the identities of ADR reporters are disclosed reporting rate } \\
\text { will increase }\end{array}$ & & & & & \\
\hline 13 & $\begin{array}{l}\text { I believe that if the identities of ADR reporters are not disclosed reporting } \\
\text { rate will decrease }\end{array}$ & & & & & \\
\hline 14 & $\begin{array}{l}\text { Pharmacovigilance should be taught only at higher levels in pharmacy } \\
\text { schools }\end{array}$ & & & & & \\
\hline 15 & I believe that adverse reactions caused by cosmetics should be reported & & & & & \\
\hline
\end{tabular}

